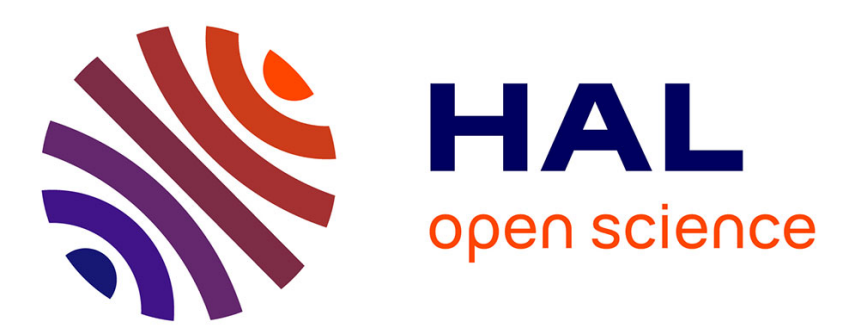

\title{
A Measurement-Based Model of Energy Consumption for PLC Modems
}

Wafae Bakkali, Mohamed Tlich, Pascal Pagani, Thierry Chonavel

\section{To cite this version:}

Wafae Bakkali, Mohamed Tlich, Pascal Pagani, Thierry Chonavel. A Measurement-Based Model of Energy Consumption for PLC Modems. ISPLC 2014: 18th IEEE International Symposium on Power Line Communications and its Applications, Mar 2014, Glasgow, United Kingdom. pp.42 - 46, 10.1109/ISPLC.2014.6812326 . hal-01009988

\section{HAL Id: hal-01009988 \\ https://hal.science/hal-01009988}

Submitted on 19 Jun 2014

HAL is a multi-disciplinary open access archive for the deposit and dissemination of scientific research documents, whether they are published or not. The documents may come from teaching and research institutions in France or abroad, or from public or private research centers.
L'archive ouverte pluridisciplinaire HAL, est destinée au dépôt et à la diffusion de documents scientifiques de niveau recherche, publiés ou non, émanant des établissements d'enseignement et de recherche français ou étrangers, des laboratoires publics ou privés. 


\title{
A Measurement-Based Model of Energy Consumption for PLC Modems
}

\author{
Wafae Bakkali $\left({ }^{*} \S\right)$, Mohamed Tlich**, Pascal Pagani ${ }^{\S}$ and Thierry Chonavel ${ }^{\S}$ \\ * Orange Labs, 2 avenue Pierre Marzin, 22300 Lannion, France \\ Email:wafae.bakkali@orange.com \\ ** INNOVAS, France \\ $\S$ Telecom Bretagne, UMR CNRS 6285 Lab-STICC, CS 83818, Technople Brest Iroise, 29238 Brest Cedex, France
}

\begin{abstract}
In this paper a detailed measurements-based analysis of the energy consumption of commercial broadband PLC modems is reported. Energy consumption measurements are carried out on the basis of pairs of many commercial PLC modems. Ethernet frames with variable sizes and bit/frame rates are sent on a modem, and received on the other modem. An analytic linear model that quantifies the energy consumption associated to Ethernet frames and PLC Physical Blocks (PBs) processing is proposed for a pair of PLC modems.
\end{abstract}

\section{INTRODUCTION}

The energy consumption of networks, devices, and systems has always been an important research issue. Several recent works have developed models of energy consumption using measurements on systems such as femtocells [1], NetFPGA Gigabit routers [2], [3], and Optical-IP routers [4]. In all these previous works, the authors proposed various formal models for the power consumption, with the device load being as the main optimization criteria. A device load is usually defined as a measure of the aggregate traffic transmitted by this device by time unit. Depending on the nature of the transmitted data, the load can be expressed in Frames/s or Bits/s. The generic model of power consumption in such systems may be defined as follows :

$$
P(l)=P_{0}+f(l)
$$

where 1 is the traffic, $P_{0}$ is the power consumption in the idle state (in Watts) (this parameter is constant for a given network or device) and $f(l)$ is an increasing load function.

In this paper we report the results we obtained for electrical energy consumption measurements on commercial PLC modems. Our contributions are as follows: first, we carried out detailed measurements of energy consumption of several pairs of PLC modems to determine energy consumption as a function of bit-rate, frame rate and frame size. To the best of our knowledge, these are the first such power consumption measurements of PLC modems presented in the open literature. Second, we developed a linear model that is able to determine the energy required to process Ethernet frames and PLC Physical Blocks in a pair of PLC modems. The rest of the paper is organized as follows. In Section II, we present the proposed linear model for PLC modems power consumption. Section III illustrates the experiment setup for measuring the power consumption. In Section IV the energy consumption model parameters are calculated, based on series of experiments. Finally, the conclusions are presented in Section V.

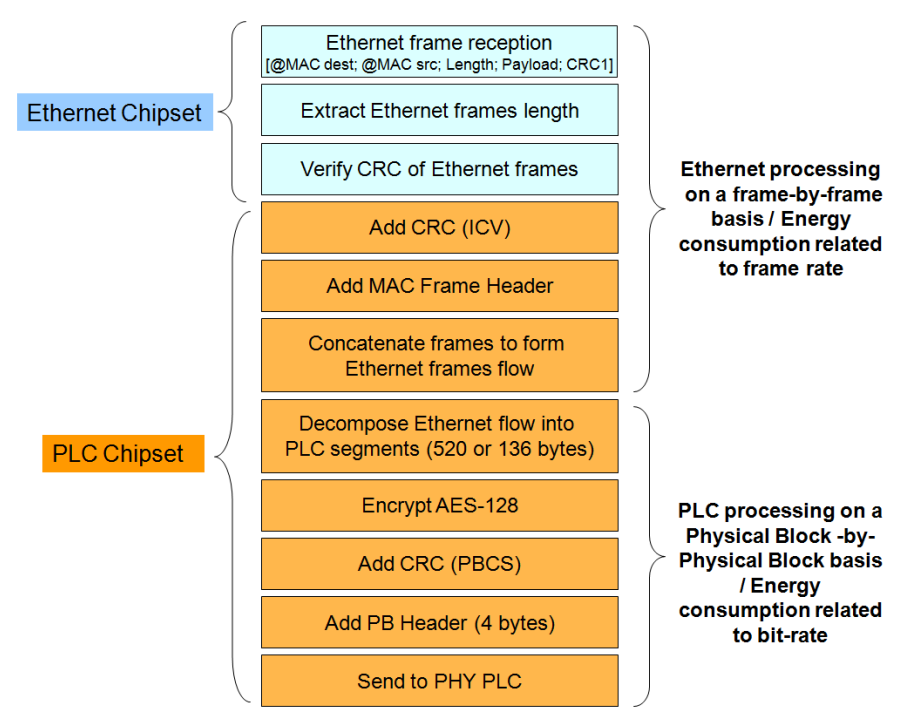

Fig. 1. Processing of an Ethernet frame through the PLC modem

\section{A LINEAR MODEL OF POWER CONSUMPTION FOR A PAIR OF PLC MODEMS}

\section{A. Processing of Ethernet frames through the PLC modem}

Fig. 1 shows a high-level view of the processing of an Ethernet frame through an HPAV [5] compliant PLC modem, which is sufficiently representative of all PLC modems. In the Data Plane, the MAC accepts MAC service data units (MSDUs) (e.g., Ethernet frames) arriving from the Convergence Layer, encapsulates them with a header, optional Arrival Time Stamp (ATS) and Checksum (ICV), then concatenate them to form Ethernet frames stream. Each MAC frame stream is divided into 512 or 136 bytes segments, each of which is encrypted and encapsulated into a serialized PHY Block (PB). The PBs are packed into a Mac Protocol Data Unit (MPDU) which is delivered to the PHY [6].

\section{B. Power consumption model}

As previously mentioned, we choose to model power consumption for pairs of PLC modems. In each pair, the first modem is considered as a transmitter and the second as a receiver. The power consumption $\mathrm{P}$ of a pair of PLC modems can be expressed as a sum of four terms, as shown below:

$$
P=C+2 \times P_{E}+E_{F} N+E_{P B} R
$$




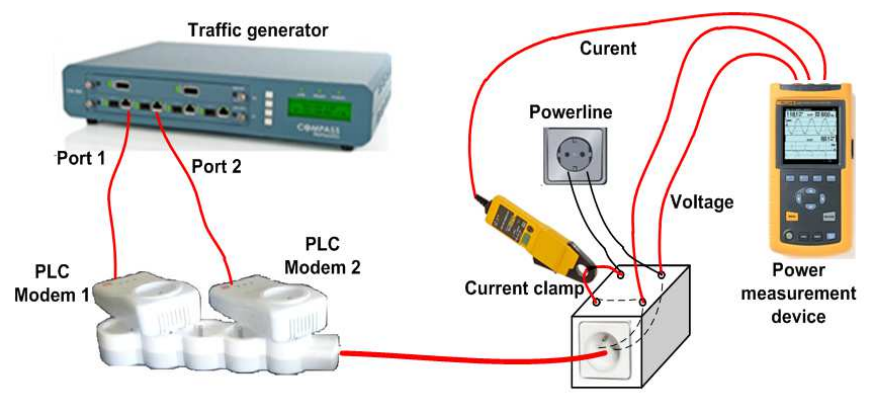

Fig. 2. Experimental setup

where

- $\quad C$ is the constant base-line power of the pair of PLC modems (in Watts) (i.e. without any Ethernet ports connected, and hence no traffic).

- $P_{E}$ corresponds to the power consumed by each Ethernet port when it is only connected and without any traffic flowing (in Watts).

- $E_{F} N$ corresponds to the power consumed for processing Ethernet frames, which is the product of per-frame processing energy $E_{F}$ and the input frame rate $\mathrm{N}$ (in frames/second). $E_{F}$ depends on frame rate because each frame that enters a PLC modem requires the same processing (i.e. Adding headers, $\mathrm{CRC}, \ldots$ ).

- $\quad E_{P B} R$ corresponds to the power consumed for processing PLC Physical Blocks, which is the product of per-byte energy $E_{P B}$ and the input data byte-rate R (in bytes/sec).

Since the frame rate $N=R / L$, Eq. (2) can be rewritten as:

$$
P=C+2 P_{E}+E_{F} R / L+E_{P B} R
$$

Under the assumption that the power consumption of the pair of PLC modems follows the model proposed above, the objective is to evaluate the parameters of Eq. (3) based on actual measurements. Sections III and IV describe in detail each experiment that helps us estimating these parameters.

\section{EXPERIMENTAL SETUP}

The test environment reported in Fig. 2 is composed of a high-precision traffic generator, 6 pairs of PLC modems, and a power quality analyzer for power measurement. Each of these devices is described below:

Traffic generator: We used a COMPASS CN-100 network analyzer [7], which is a high-precision hardware traffic analyzer with capabilities for generating Ethernet frames with various configurable parameters such as bandwidth utilization, frame rate, frame payload, and frame length to simulate different network traffic conditions and analyze the performance of the link. We connected the two Ethernet ports of the CN100 analyzer to the two ports of the pair of PLC modems. In our experiments Ethernet port 1 is connected to the transmitter modem (PLC modem 1) and Ethernet port 2 to the receiver modem (PLC modem 2).
TABLE I. LIST OF TESTED PLC MODEMS

\begin{tabular}{|l|l|l|l|l|l|}
\hline $\begin{array}{l}\text { PLC } \\
\text { Modems }\end{array}$ & Standard & Chipset & $\begin{array}{l}\text { Ethernet } \\
\text { port } \\
\text { speed } \\
\text { (Mbps) }\end{array}$ & $\begin{array}{l}\text { Maximum } \\
\text { PHY bit- } \\
\text { rate } \\
\text { (Mbps) }\end{array}$ & $\begin{array}{l}\text { Useful } \\
\text { bit-rate } \\
\text { (Mbps) }\end{array}$ \\
\hline M1 & HD-PLC & KHN13100 & 100 & 240 & 60 \\
\hline M2 & HPAV & $\begin{array}{l}\text { Atheros } \\
\text { INT 6400 }\end{array}$ & 100 & 200 & 90 \\
\hline M3 & HPAV & $\begin{array}{l}\text { Atheros } \\
\text { AR6405 }\end{array}$ & 100 & 200 & 80 \\
\hline M4 & HPAV & $\begin{array}{l}\text { Atheros } \\
\text { AR7400 }\end{array}$ & 1000 & 500 & 230 \\
\hline M5 & HPAV & $\begin{array}{l}\text { Atheros } \\
\text { INT6400 }\end{array}$ & 100 & 200 & 80 \\
\hline M6 & HPAV & $\begin{array}{l}\text { Atheros } \\
\text { INT7400 }\end{array}$ & 1000 & 500 & 90 \\
\hline
\end{tabular}

TABLE II. BASELINE POWER CONSUMPTION FOR THE 6 PAIRS OF PLC MODEMS

\begin{tabular}{|c|c|}
\hline PLC modems & Baseline power $C$ \\
\hline M1 & $4.4 \mathrm{~W}$ \\
\hline $\mathrm{M} 2$ & $3 \mathrm{~W}$ \\
\hline $\mathrm{M} 3$ & $1.2 \mathrm{~W}$ \\
\hline $\mathrm{M} 4$ & $5 \mathrm{~W}$ \\
\hline $\mathrm{M} 5$ & $4 \mathrm{~W}$ \\
\hline $\mathrm{M} 6$ & $6.2 \mathrm{~W}$ \\
\hline
\end{tabular}

PLC modems: We measured power consumption for 6 pairs of PLC commercial modems M1, M2, M3, M4, M5 and M6 using HPAV and HD-PLC [8] standards. Table I shows details about the modems used.

Power measurement device: We used a Fluke 43B Power Quality Analyzer [9] to measure the electrical energy consumption of the PLC plugs. This instrument has two input channels and can measure both voltage and current simultaneously and automatically takes the phase angle into account. In our experiments the pair of PLC modems is plugged to a single power strip and connection is made as shown in Fig. 2. The Fluke i30s AC/DC current clamp is used with the Fluke 43B Power Analyzer for current measurements.

\section{ESTIMATION OF THE PARAMETERS OF THE POWER CONSUMPTION MODEL}

\section{A. Baseline power $C$}

We measured the baseline power consumed by each pair of PLC modems when they are idle and Ethernet ports are not connected. We repeated our measurements several times (each 10 seconds during 2 minutes) and computed their average value. Table II shows the average baseline power consumption for the 6 pairs of PLC modems, while Fig. 3 shows the measured electrical power consumption versus time. At this point we note that depending on the chipset and standard used, baseline powers of various modem pairs can be significantly different. We also mention that some manufacturers propose advanced Power-Saving modes that reduce energy consumption when there is no data transmission or reception (Case of M3).

\section{B. Ethernet per-port power $P_{E}$}

After measuring the baseline power, we plugged the Ethernet cables into each PLC modem port to activate it. We did 


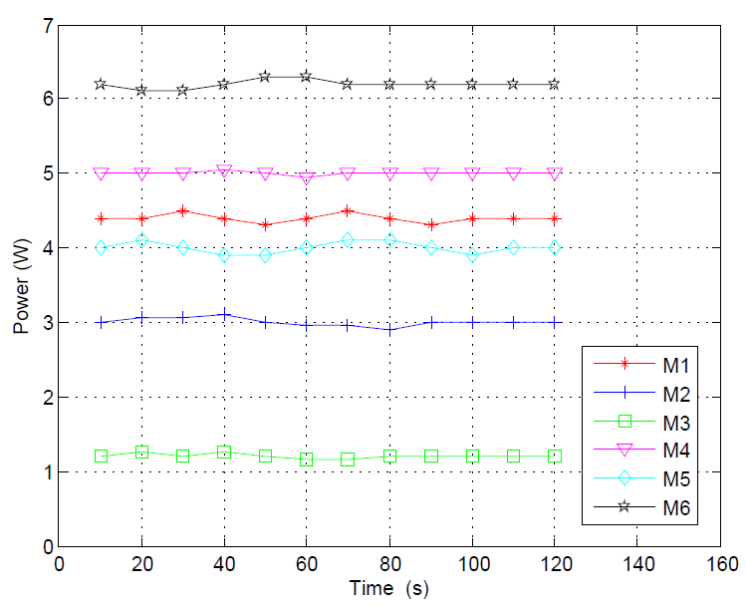

Fig. 3. Measured power consumption of the PLC modems when they are idle and Ethernet ports are not connected

TABLE III. ETHERNET PER-PORT POWER $P_{E}$

\begin{tabular}{|c|c|c|c|}
\hline PLC modems & $C(W)$ & $2 P_{E}(W)$ & $C+2 P_{E}(W)$ \\
\hline M1 & 4.4 & $2 \times 0.2$ & 4.8 \\
\hline M2 & 3 & $2 \times 0.5$ & 4 \\
\hline M3 & 1.2 & $2 \times 0.3$ & 1.8 \\
\hline M4 & 5 & $2 \times 0.6$ & 6.2 \\
\hline M5 & 4 & $2 \times 0.3$ & 4.6 \\
\hline M6 & 6.2 & $2 \times 1.05$ & 8.3 \\
\hline
\end{tabular}

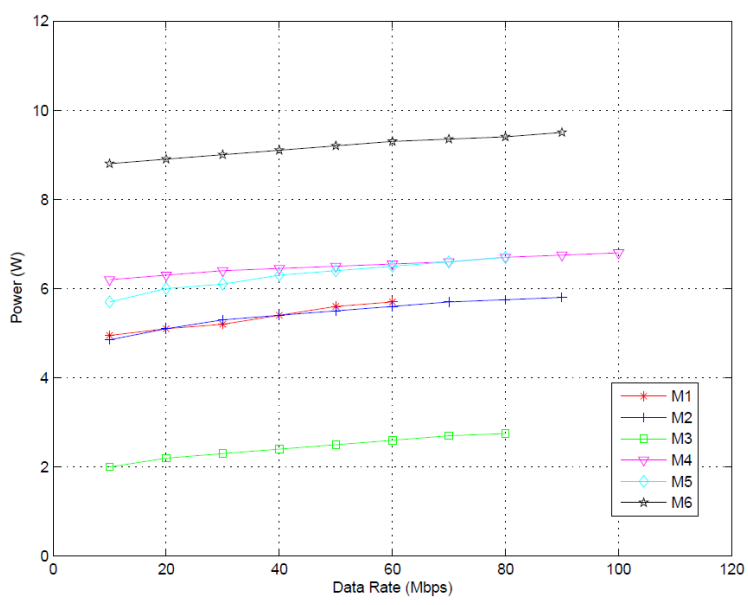

Fig. 4. Power consumption versus bit-rate for fixed frame size $\mathrm{L}=1500$ Bytes

this by adding one cable at a time and no traffic was involved. Results show that for a pair of PLC modems, the increase in power was almost perfectly linear: each plugged Ethernet port brings a constant power value $P_{E}$ (see Table III). This increase in power consumption can mainly be attributed to the fact that most of the modules of the Ethernet and PLC chips are continuously active as soon as a cable is plugged in, leading to an energy consumption that is large and independent of the traffic load [10]. It can be observed (from Table III) that perport power consumption is higher when using 1000 BASE-T port (case of modems M4 and M6). 1000 BASE-T Ethernet chips are in fact consuming more energy than 100 BASE-T (100 Mb/s) chips.

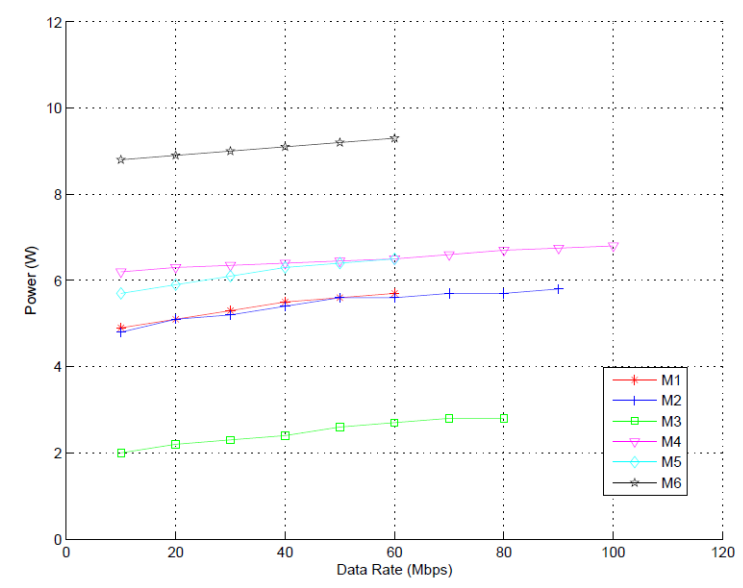

Fig. 5. Power consumption versus bit-rate for fixed frame size $\mathrm{L}=1000$ Bytes

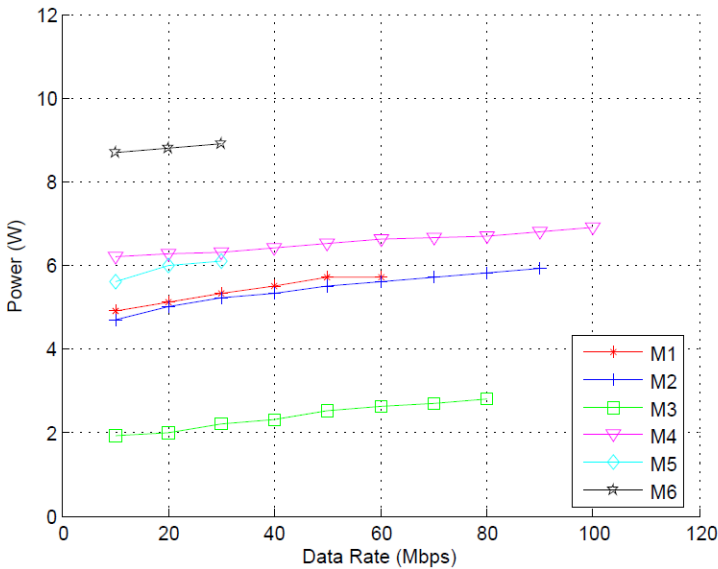

Fig. 6. Power consumption versus bit-rate for fixed frame size $\mathrm{L}=500$ Bytes

\section{Ethernet frames and PLC Physical Blocks processing en- ergies}

This experiment aims to estimate Ethernet frames and PLC Physical Blocks processing energies, respectively denoted $E_{F}$ and $E_{P B}$. To do so, we fix the frame size (L Bytes), and send an IPv4 stream of frames from the CN-Compass Network traffic generator to the transmitter PLC modem (modem1). The experiment is repeated for different values of bit-rates (10 Mbps, $20 \mathrm{Mbps}$, etc.). The whole process is repeated for several frame sizes to get more exact estimates for $E_{F}$ and $E_{P B}$. Bit-rates are increased up to $80 \mathrm{Mbps}$ in most of the cases without resulting in any Ethernet frame loss. This high bit-rate is obtained thanks to the small distance between transmitter and receiver modems (signal attenuation is negligible). Fig. 4 reports the measurements of the power consumption of the 6 pairs of PLC modems when transmitting frames of constant size from the port 1 (which is connected to modem 1) of the CN-100 Compass network analyzer to port 2 (modem 2). In this work, we only report measurements when transmission rate is equal to reception rate (no frame loss). Fig. 4 shows how power consumption changes as a function of bit-rate for a fixed frame size of 1500 Bytes. Measured values for other frames sizes are shown in Fig. 5 (1000 Bytes) and Fig. 6 (500 Bytes). 
We can see that:

- The power consumption increases almost linearly with bit-rate.

- The increase of power consumption with bit-rate is higher for the small frames than for the large frames. For example, for PLC modems M4, energy increases by $0.007 \mathrm{~W} / \mathrm{Mbps}$ with 500 Bytes frames and 0.0062 W/Mbps with 1500 Bytes frames. This is in accordance with the third term in Eq.(3). Indeed, when the frame size increases, the number of frames sent per second decreases as the data load in Mbps is held fixed. Per frame overheads (framing, ARQ, etc) are therefore reduced.

- The power consumption reaches a plateau as the offered load attains the network capacity. For example, for modems M1, with 500 Bytes frames, the maximum network throughput is observed to be $50 \mathrm{Mbps}$. At offered loads above this level, significant packet loss is observed. Note that this effect is channel dependent and will not be taken into account in our proposed model.

The Ethernet frames and PLC Physical Blocks processing energies can now be deduced as follows: we begin by taking the partial derivative of Eq.(3) with respect to the input data rate $R$,

$$
\partial P / \partial R=E_{F} / L+E_{P B}
$$

For a given value of frame size $\mathrm{L}$, the left side of the above equation, namely $\partial P / \partial R$, can be deduced from the slopes of the corresponding curves in Fig. 4, Fig. 5 and Fig. 6. We can notice that for each PLC modem the curve for a frame size $\mathrm{L}$ is represented by a straight line of the form $P_{L}=$ $a_{L} \times r+b_{L}$ where $r$ is the input data rate in bit/s $(r=8 R), a_{L}$ is the slope for the corresponding curve, and $\partial P_{L} / \partial R=8 a_{L}$ (the multiplier 8 comes from the fact that $\mathrm{R}$ in Eq.(3) is in bytes-per-second while figures 4 to 6 show bit-rates in bitsper-second). We note here that the Figs 4 to 6 show that the slope decreases with increasing frame size L, confirming that for the same increase in bit-rate, smaller frames incur a larger incremental energy overhead. From the Eq.(4) we can then deduce that:

$$
8 L_{j} a_{L_{i j}}=E_{F_{i}}+L_{j} E_{P B_{i}}
$$

Where

- $j \in 1,2,3$ represents the packet size index within the packet sizes $L_{j}=(500,1000,1500)$.

- $\quad i \in 1,2,3,4,5,6$ represents the modem index within the modem family: M1, M2, M3, M4, M5, M6

- $\quad$ Figures 4 to 6 lead to the slopes

$$
a_{L_{i j}}=\left(\begin{array}{ccc}
0.0171 & 0.0163 & 0.0156 \\
0.0142 & 0.0117 & 0.0113 \\
0.0133 & 0.0119 & 0.0104 \\
0.0070 & 0.0064 & 0.0062 \\
0.0250 & 0.0163 & 0.0135 \\
0.0100 & 0.0100 & 0.0087
\end{array}\right)
$$

Corresponding equations $P_{L}=a_{L} \times r+b_{L}$ are reported in Table IV.
TABLE IV. EQUATIONS $P_{L}=a_{L} \times r+b_{L}$ WHEN FIXING THE FRAME SIZE $L$ AND VARYING THE BIT-RATE $r$

\begin{tabular}{|l|l|l|l|}
\hline & $P_{1500 \text { Bytes }}$ & $P_{1000 B y t e s}$ & $P_{500 \text { Bytes }}$ \\
\hline M1 & $0.0156 r+4.7800$ & $0.0163 r+4.7800$ & $0.0171 r+4.7667$ \\
\hline M2 & $0.0113 r+4.8819$ & $0.0117 r+4.8500$ & $0.0142 r+4.7028$ \\
\hline M3 & $0.0104 r+1.9625$ & $0.0119 r+1.9393$ & $0.0133 r+1.7750$ \\
\hline M4 & $0.0062 r+6.1850$ & $0.0064 r+6.1571$ & $0.007 r+6.1438$ \\
\hline M5 & $0.0135 r+5.6821$ & $0.0163 r+5.5800$ & $0.025 r+5.4000$ \\
\hline M6 & $0.0087 r+8.7389$ & $0.01 r+8.7000$ & $0.01 r+8.6000$ \\
\hline
\end{tabular}

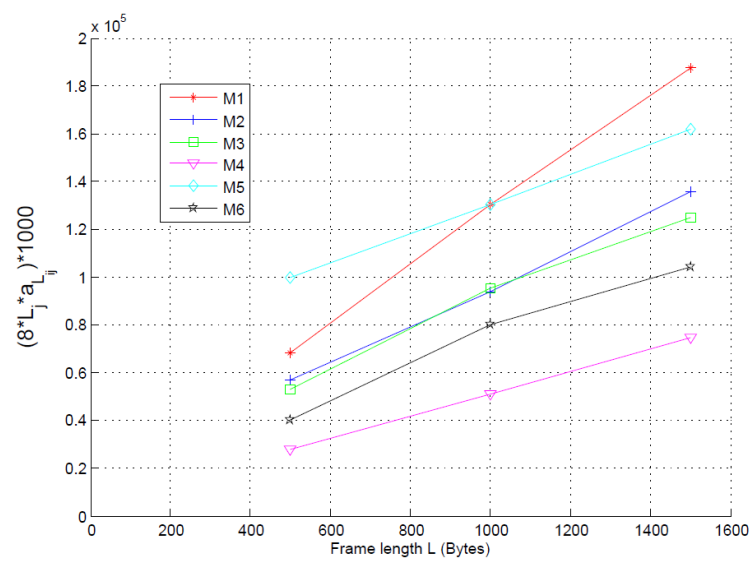

Fig. 7. Fitting data to estimate energy model parameters

TABLE V. CORRESPONDING EQUATIONS OF CURVES AT FIG. 7

\begin{tabular}{|c|c|}
\hline PLC Modems & Equations $E_{F_{i}}+L_{j} E_{P B_{i}}$ \\
\hline M1 & $118.8 L_{j}+9866.7$ \\
\hline M2 & $78.8 L_{j}+16533$ \\
\hline M3 & $71.6 L_{j}+19467$ \\
\hline M4 & $46.4 L_{j}+4800$ \\
\hline M5 & $62 L_{j}+68800$ \\
\hline M6 & $64.4 L_{j}+10400$ \\
\hline
\end{tabular}

Eq. (5) gives us for each pair of PLC modems $i$, three equations (given by the three frame sizes) to determine the two parameters $E_{F_{i}}$ and $E_{P B_{i}}$. Two equations are then used for calculation and the third for validation. In Fig. 7 are given for each pair of PLC modem $i$ the three left side values $\left(8 L_{j} a_{L_{i j}}\right)$ of Eq.(5) as a function of frame sizes $L_{j}, j \in 1,2,3$. The fact that the third point of each curve fits almost perfectly to the straight line built by the other two points validates the estimates of $E_{F_{i}}$ and $E_{P B_{i}}$. The slope of these straight lines corresponds to Ethernet frame processing Energy $E_{F_{i}}$, while the intercept gives us the PLC Physical Blocks processing energy $E_{P B_{i}}$. Table $\mathrm{V}$ presents corresponding equations $E_{F_{i}}+L_{j} E_{P B_{i}}$ for the 6 PLC modems, $(i \in 1, \ldots, 6)$.

\section{Summary and Discussion}

Table VI summarizes our proposed model parameters for the energy consumption of tested PLC modems. Fig. 8 presents for each pair of PLC modems and when considering a frame size $L=1500$ Bytes and a bit-rate $r=60$ Mbps:

- Static and dynamic consumed power consumptions. Static power consumption is the sum of baseline power $\mathrm{C}$ and per-port Ethernet power $P_{E}$ (without traffic flowing through PLC modems) and dynamic power 


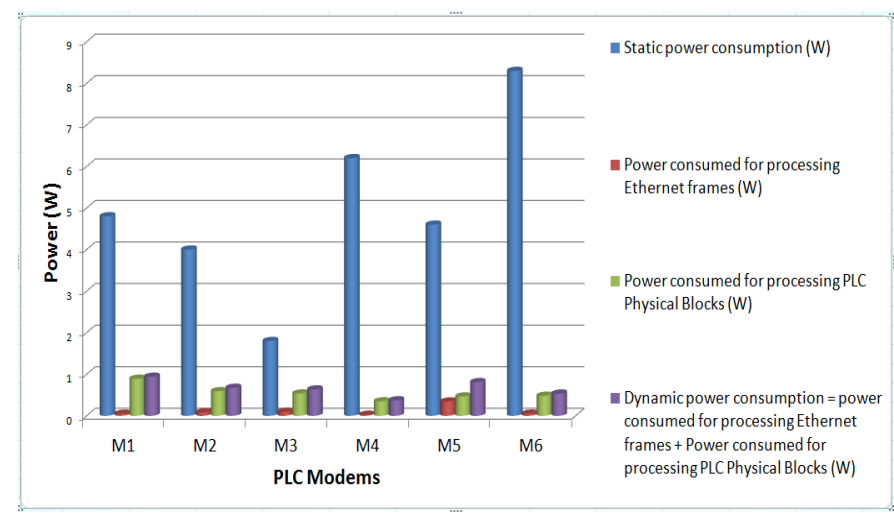

Fig. 8. Power consumption model parameters calculated for a frame size $L=1500$ Bytes and a bit-rate $r=60 \mathrm{Mbps}$

TABLE VI. SUMMARY OF THE POWER PROFILE FOR THE 6 PAIRS OF PLC MODEMS

\begin{tabular}{|l|l|l|l|l|}
\hline $\begin{array}{l}\text { PLC } \\
\text { modems }\end{array}$ & $\begin{array}{l}\text { Baseline } \\
\text { power } \\
\mathrm{C}(\mathrm{W})\end{array}$ & $\begin{array}{l}\text { Ethernet per- } \\
\text { port power } \\
2 \times P_{E}(\mathrm{~W})\end{array}$ & $\begin{array}{l}\text { Ethernet } \\
\text { frames } \\
\text { processing } \\
\text { energy } \\
E_{F}(\mathrm{~nJ})\end{array}$ & $\begin{array}{l}\text { PLC frames } \\
\text { processing } \\
\text { energy } \\
E_{P B}(\mathrm{~nJ})\end{array}$ \\
\hline M1 & 4.4 & $2 \times 0.2$ & $9.9 \times 10^{3}$ & 118.8 \\
\hline M2 & 3.0 & $2 \times 0.5$ & $16.5 \times 10^{3}$ & 78.8 \\
\hline M3 & 1.2 & $2 \times 0.3$ & $19.5 \times 10^{3}$ & 71.6 \\
\hline M4 & 5.0 & $2 \times 0.6$ & $4.8 \times 10^{3}$ & 46.4 \\
\hline M5 & 4.0 & $2 \times 0.3$ & $68.8 \times 10^{3}$ & 62.0 \\
\hline M6 & 6.2 & $2 \times 1.1$ & $10.4 \times 10^{3}$ & 64.4 \\
\hline
\end{tabular}

consumption is the power consumed for processing Ethernet frames and PLC Physical Blocks (power associated to the term: $E_{F} N+E_{P B} R$ ).

- Ethernet frame processing Energy and Physical Blocks processing Energy.

Fig. 8 indicates that PLC Physical Blocks processing power consumption is higher than Ethernet frame processing power consumption.

Static power consumption of PLC modems is the largest component of the total power consumption. That means that commercial PLC modems consume most of their power just to be on, and the impact of traffic load on power consumption is relatively small.

\section{CONCLUSion}

This paper has investigated the power consumption of PLC modems. We have proposed a power consumption model based on measurements carried out on many commercial PLC modems. In this model, the energy consumption for Ethernet frame processing and for Physical Blocks processing are separately quantified. Such an experimental campaign permitted us to ascertain the impact of traffic on the energy efficiency of PLC modems. In all cases, the total energy consumption is dominated by the static component (when no traffic is flowing through the pair of PLC modems). For the dynamic component (part of energy associated to flowing traffic), Physical Blocks processing energy appears to be the most critical element. The obtained results suggest that future power improvements should concentrate on static energy reduction techniques, mainly power-saving modes. Then, dynamic power consumption is to be investigated since it can be an important contributor to total power consumption (e.g., about $25 \%$ of total power consumption in the case of Modems M3). For future extensions of this work, we expect to modify the proposed model to include the differentiation between transmitside energy associated with transmission of Ethernet frames and receive-side energy associated with reception of Ethernet frames.

\section{ACKNOWLEDGMENT}

This work was supported by the French project FUI14 GREENCoMM.

\section{REFERENCES}

[1] R. Riggiol, D. Leith, "A Measurement-Based Model of Energy Consumption in Femtocells", Wireless Days (WD), IFIP, Germany, 2012.

[2] V. Sivaraman, A. Vishwanath, Z. Zhao and C. Russell, "Profiling PerPacket and Per-Byte Energy Consumption in the NetFPGA Gigabit Router", Proc. IEEE INFOCOM Workshop on Green Communications and Networking, China, Apr 2011.

[3] A. Vishwanath, Z. Zhao, V. Sivaraman and C. Russell, "An Empirical Model of Power Consumption in the NetFPGA Gigabit Router", Proc. IEEE Advanced Networks and Telecommunication Systems, Mumbai, India, Dec 2010.

[4] A. Vishwanath, J. Zhu, K. Hinton, R. Ayre, and R. Tucker, "Estimating the Energy Consumption for Packet Processing, Storage and Switching in Optical-IP Routers", Optical Fiber Communication Conference Anaheim, California, United States, March 17-21, 2013.

[5] Home Plug Alliance. Website: http://www.homeplug.org, HomePlug AV specifications. Version 1.1, May 2007.

[6] HomePlug Powerline Alliance,"HomePlug AV White Paper", August 18, 2005 (last read May 25, 2006, http://www.homeplug.org/tech/whitepapers/HPAV-WhitePaper_050818.pdf).

[7] COMPASS $\mathrm{CN}-100$ network analyzer, "CN-100 Manager User Manual", June 2007, http://www.compassnettest.com/wpcontent/uploads/2011/09/CN100-User-Manual.pdf.

[8] HD-PLC Alliance, Website: http://www.hd-plc.org/.

[9] Fluke 43b power quality analyzer, "Fluke 43B Power Quality Analyzer Users Manual", April 2001, rev 2, 12-2008, http://assets.fluke.com/manuals/43b__umeng0200.pdf

[10] Charles E. Spurgeon, "Ethernet: The Definitive Guide", Chapter 6, Published February 16th 2000 by O'Reilly Media (first published January 1st 2000). 